\title{
Syndrome of agitated delirium and visual impairment: a manifestation of medial temporo-occipital infarction
}

\author{
J OSE L. MEDINA, S U DHA N U CHOKROVERTY, A N \\ F R A N K A. R U B I N O
}

From the Veterans Administration Hospital, Hines, Neurology Service and Loyola University Stritch School of Medicine, Maywood, Illinois, USA

SUMMARY Three patients presented with sudden visual impairment followed by agitated delirium one to three days later. Examination revealed marked agitation, dementia, and loss of vision. Computerised axial tomography demonstrated temporo-occipital infarctions. All recovered from the agitated state in four days to two months, but their visual impairment and dementia persisted one to four years later.

Recently Horenstein et al. (1967) and Medina et al. (1974) have described agitated delirium and visual impairment in infarctions of the medial temporo-occipital region. In the previous reports all patients died in weeks to months. The purpose of this report is threefold: (1) to describe three additional cases emphasising this mode of presentation which, though not specific, is distinctive enough for medial temporo-occipital infarction; (2) to point out a different mode of onset from the previous reports, and (3) to document recovery from the agitated state with prolonged survival.

\section{Case 1}

A 58 year old man had a sudden onset of left hemiparesis and hemianopsia in 1963. He made a good recovery, and continued working until October 1972 when he suddenly became blind. The next day he became very agitated, confused, and belligerent, had frequent nightmare-like visual hallucinations and needed to be restrained. Four days later, the delirium subsided and he was noted to be very forgetful but denied any blindness. Because of the persistence of these symptoms, he was transferred to Hines Veterans Administrative Hospital in November 1973.

On examination he was oriented to time, place,

Address for reprint requests: Jose L. Medina, Neurology Service (127), VA Hospital, Hines, IL 60141, USA.

Accepted 12 April 1977 and person, and had good insight about his disabilities. Judgement, calculations, and remote memory were normal, but he forgot any name repeated to him two minutes before. He had blindness but the pupillary responses to light were normal. The other notable findings consisted of mild left hemiparesis and hemihypaesthesia. An electroencephalogram (EEG) showed focal slow waves in the left temporoparieto-occipital regions and a

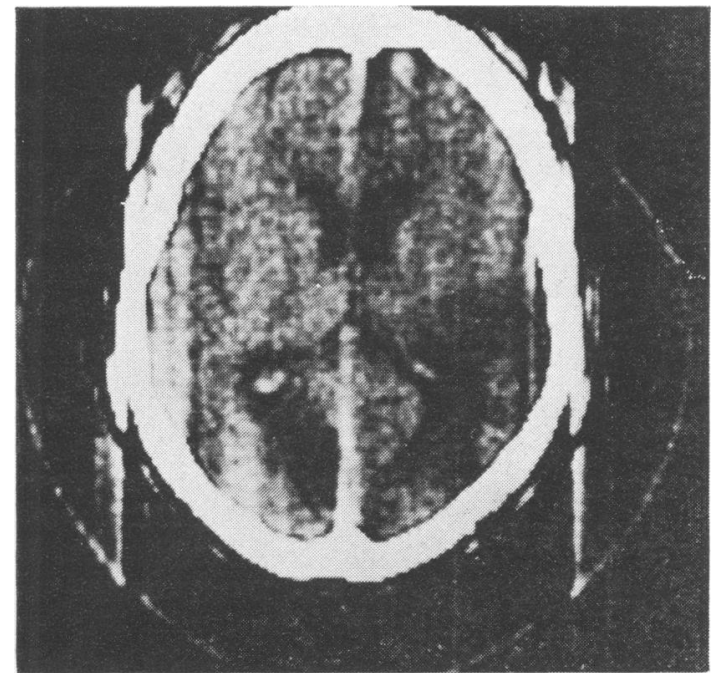

Fig. 1 Computerised axial tomography showing areas of mixed densities in the right occipito-temporoparietal and left medial occipital regions (case 1). 
brain scan demonstrated increased uptake in the right parieto-occipital area. Cerebral evoked potential study showed impairment of all components of the visual evoked responses bilaterally with slightly more marked attenuation on the right, but normal somatosensory responses. Computerised axial tomography revealed areas of mixed density in the right occipito-temporoparietal and left medial occipital regions consistent with bilateral encephalomalacias (Fig 1). The rest of the investigations, including right brachial and left carotid angiograms, were normal. During the first six months of hospitalisation, his condition improved. He occasionally missed a name out of three repeated to him a few minutes before, and recovered the vision in the right upper quadrants. He was discharged home in April 1974. Since then he has been living alone and taking good care of himself.

\section{Case 2}

A 37 year old right handed man suddenly developed blurring of vision, difficulty in walking, and headache in December 1971. Twenty-four hours later he became very agitated, disoriented, and began to shout and use foul language. He had continuous visual hallucinations consisting of pipes

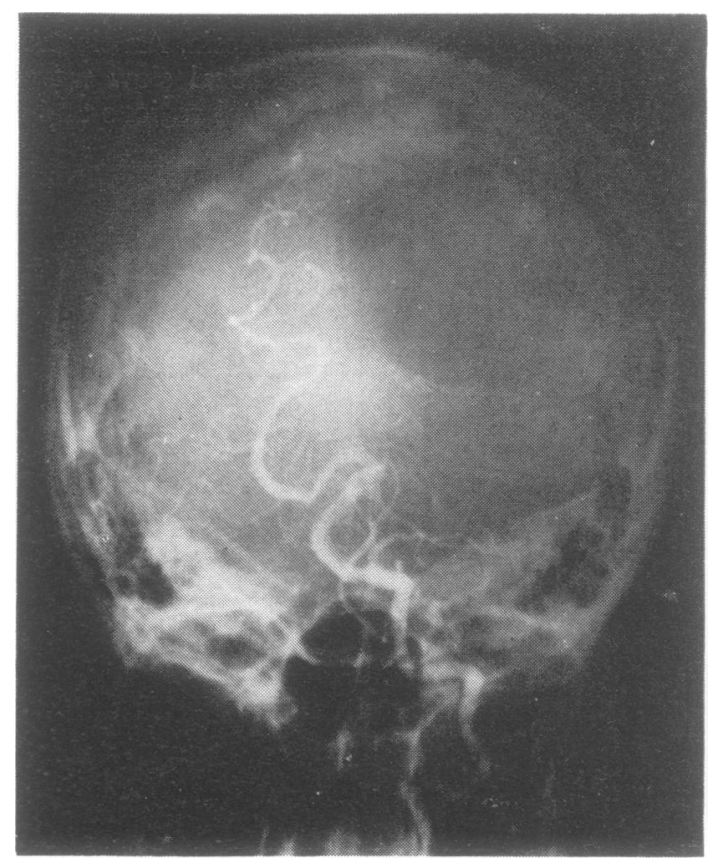

Fig. 2 Left vertebral angiogram showing obstruction of the left posterior cerebral artery (case 2). sticking out of his head and his wife's head. He $\stackrel{\mathbb{D}}{=}$ tried to remove the pipes from his wife whoo thought he was going to strangle her. She im $\frac{\text { 응 }}{4}$ mediately took him to a local hospital where these symptoms persisted for two weeks. After thes agitated state disappeared, right homonymous? hemianopsia and memory loss were noticed. Five days later, he was discharged home. His wife observed that the patient was very forgetful and un $-\vec{z}$. able to read. In addition, there were impotency, absence of spontaneous nocturnal erections, ande lack of interest in sexual matters. In January 1975 흠 he was admitted to Hines VA Hospital for re $\frac{\text { - }}{-}$ evaluation. He was oriented to person and place, $\stackrel{\mathbb{Q}}{\circ}$ but not to time. His digit span consisted of sixis numbers and he was only able to remember two $-\vec{O}$ out of three names repeated to him three minutes:before. Remote memory was also poor; he forgot $\vec{\omega}$ how many children he had and the names of some? of his closest relatives. Abstract thinking was very deficient and the affect was flat. Writing was fluent, but he was unable to read unless the words? were spelled aloud. He could not name colours but naming of objects was normal. He had a righto homonymous hemianopsia and minimally creased muscle stretch reflexes on the right siff. An EEG showed a slow wave focus over the leftes temporal region. Somatosensory cerebral evoked $\mathbb{D}$ responses after stimulation of the median nervgs $\mathbb{\mathbb { D }}$ at the wrists were normal bilaterally, but visu 1

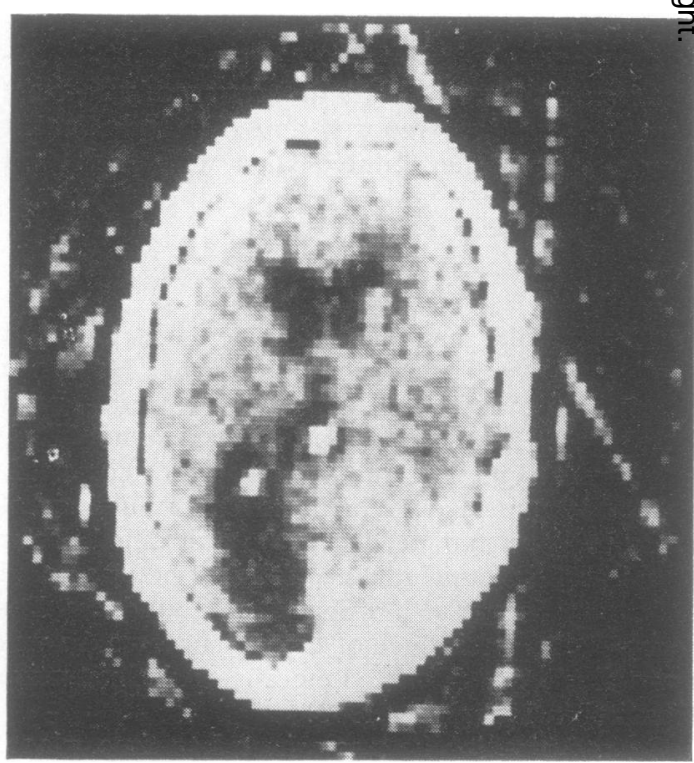

Fig. 3 Computerised axial tomography showing radiolucent area in the left medial temporo-occipital region (case 2). 
evoked responses showed attenuation of all components in the left occipital region. Cerebral angiography demonstrated an occlusion of the left posterior cerebral artery (Fig. 2), and computerised axial tomography showed an infarct in the left medial temporo-occipital region (Fig. 3). His neurological status has remained unchanged since then.

\section{Case 3}

In July 1974, a 54 year old man had right hemiparesis from which he made a good recovery. In December 1974 he had sudden onset of blindness and was admitted to a local hospital. Three days after admission he developed agitation, confusion, and aggressiveness. He shouted and threw objects at the nursing personnel and would frequently use obscene language. Ten days after admission he had sudden onset of left hemiparesis. Three weeks later the hemiparesis was markedly improved, but the visual and mental symptoms remained unchanged. The patient was finally transferred to Hines VA Hospital in February 1975. On examination, he was very belligerent, refusing to answer any questions, and he only said 'physicians are knuckleheads; I was railroaded into admission; and this examination is terminated'. He was blind but had normal pupillary light reaction. Motor examination was unremarkable except for slight flattening of the right nasolabial fold. Snout, sucking, and bilateral palmomental reflexes were present. Administration of thiothixene $8 \mathrm{mg}$ daily

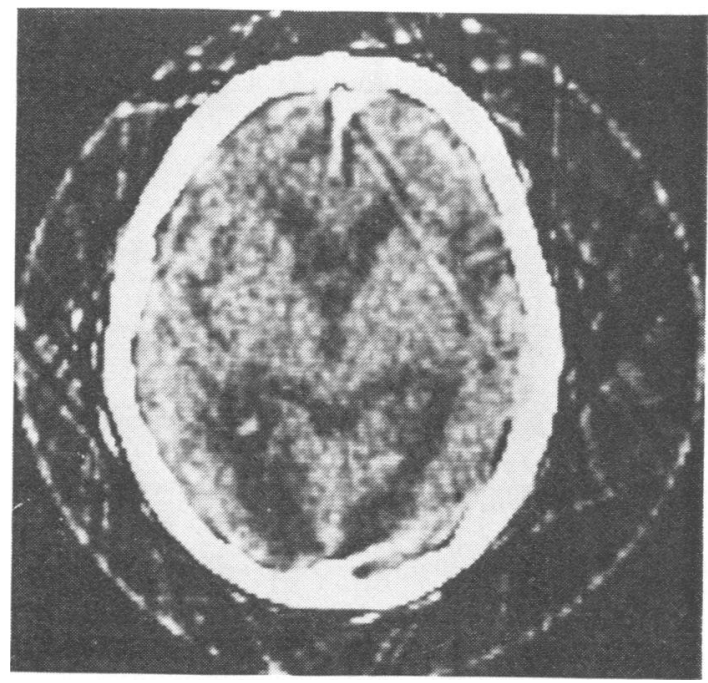

Fig. 4 Computerised axial tomography showing irregular radiolucencies in both medial temporooccipital regions and right Sylvian area (case 3). resulted in improvement of his behaviour up to the point that he was able to communicate. He was disoriented to time, but oriented to place and person. His remote memory was poor. Immediate recall was intact; however, he did not remember the name of any object after one minute. Language testing revealed no aphasia. Abstract thinking, attention and concentration were poor. An EEG showed intermittent delta waves over both temporal regions. Computerised axial tomography disclosed an irregular radiolucency in both medial and temporo-occipital regions and right Sylvian area (Fig. 4). His mental status, behaviour and vision remained stationary.

\section{Comments}

The three patients described above developed the syndrome of agitated delirium and visual impairment as a result of unilateral (case 2), or bilateral medial temporo-occipital infarctions (cases 1 and 3). Cerebral angiograms, performed in cases 1 and 2 , showed an occlusion of the posterior cerebral artery in only one patient (case 2). However, computerised axial tomography delineated the lesions in all of them.

In previous articles Horenstein et al. (1967) and Medina et al. (1974) emphasised the simultaneous, abrupt onset of agitated delirium and visual disturbance, and the fatal outcome. However, the patients reported here differed by their mode of presentation, recovery from agitation, and prolonged survival. The delirious state occurred one to three days after sudden visual impairment and lasted for four days to two months. Our patients are still alive one to four years after the onset of the syndrome. During the agitated state the patients displayed marked excitement, confusion, aggressiveness, frequent shouting and swearing. In addition, patients 1 and 2 had prominent visual hallucinations which could have contributed to their d:sturbed behaviour. After the three patients recovered from the agitated state, some visual and intellectual deficits remained. Patient 1 regained part of his vision and had only a mild recent memory loss, but the other two patients did not recover any vision and had conspicuous mental sequelae. Dementia after a unilateral left medial temporo-occipital encephalomalacia (case 2) is an unusual finding (Benson et al., 1974). However, a small infarct in the contralateral region remained a possibility in our patient. An interesting incidental finding in patient 2 consisted of loss of libido and impotence. These symptoms are known to occur occasionally in temporal lobe lesions (Hierons, 1971). 
Release of the medial temporal region from other cortical areas or excitation of certain structures in the medial temporal lobe most likely caused agitated delirium in our patients. Experimental studies have given rise to both aggressiveness (Bard and Mountcastle, 1948), and placidity (Kluver and Bucy, 1939), after bilateral temporal lobe ablations. Furthermore, temporal lobe infarctions without agitated state have been reported (Delay and Brion, 1962; DeJong et al., 1969; Benson et al., 1974). Therefore, the exact anatomical substrate in the temporal lobe for agitated delirium in our patients must remain speculative. The patients with acute confusional states after right frontoparietal infarction as described by Mesulam et al. (1976) appeared to differ from our patients because of admixture of prominent language dysfunction with mild agitation of brief duration.

We would suggest that the most probable lesion for sudden cortical visual loss accompanied by agitated delirium either immediately or shortly thereafter is an infarction of the medial temporooccipital region bilaterally or unilaterally. Its course may be one of continuous delirium until death in several weeks or months or recovery with residual dementia and visual deficit.

\section{References}

Bard, P., and Mountcastle, V. B. (1948). Some forebrain mechanisms involved in expression of rage with special reference to suppression of angry be havior. Research Publications of the Association of Nervous and Mental Diseases, 27, 362-404.

Benson, F., Marsden, C. D., and Meadows, J. C (1974). The amnesic syndrome of posterior cerebrape artery occlusion. Acta Neurologica Scandinavica? 50, 133-145.

DeJong, R. N., Itabashi, H. D., and Olson, J. R (1969). Memory loss due to hippocampal lesions:A case report. Archives of Neurology (Chicago), $20 \hat{\overline{2}}$ 339-348.

Delay, J., and Brion, S. (1962). Les Demences Tardives p. 164. Masson et Cie: Paris.

Hierons, R. (1971). Impotence in temporal lobe lesions $\frac{\text { का }}{\frac{1}{2}}$ Journal of Neuro-visceral Relations, Supplement, 10? 477-481.

Horenstein, S., Chamberlain, W., and Conomy, $\mathbf{J}_{-}$ (1967). Infarctions of the fusiform and regions with agitated delirium and hemianopsia. Transactions of $\overrightarrow{\mathrm{f}}$ the American Neurological Association, 92, 85-89\%

Kluver, H., and Bucy, P. C. (1939). Preliminary analy sis of functions of the temporal lobes in monkeys 0 Archives of Neurology and Psychiatry (Chicago), 42. 979-1000.

Medina, J. L., Rubino, F. A., and Ross, E. (1974) Agitated delirium caused by infarctions of the? hippocampal formation and fusiform and ling gyri: A case report. Neurology (Minneapolis), $\frac{24}{\mathrm{D}}$.
1181-1183.

Mesulam, M-M, Waxman, S., Geschwind, N., amdD Sabin, T. D. (1976). Acute confusional states whth right middle cerebral artery infarctions. Journal 8 Neurology, Neurosurgery, and Psychiatry, 39, 84-89.8 